\title{
Age estimation and its adaptation of the Turkish children using modified demirjian's method
}

\begin{abstract}
Background: Age estimation is important in the fields of dentistry and Demirjian's method is used generally. Many different methods have been used to date and none of them meet the standards as Demirjian's method since 1973. However, this method may not be valid in some populations. The aim of this study is to evaluate the modified Demirjian's method on Turkish children and young adults.
\end{abstract}

Methods: The scoring table of Demirjian has been modified to Turkish children - young adults and new dental maturity score were obtained. In addition, the effect of gender on the crown and root formation were assessed using the Mann-Whitney-u test and the table was created with divided into ages. The dental maturity of 848 healthy children and young adults (445 females 403 males) aged between 10 and 19years were studied with dental panoramic tomograms. Two raters evaluated the right third mandibular molar according to development stages of Modified Demirjian's.

Results: The crown and root formation were statistically significant in the 17.0-17.9 age group between females and males $(\mathrm{P}=006)$. Descriptive analysis showed that $\mathrm{F}$ stage is the shortest period. Modified Demirjian method is adapted to the Turkish population.

Conclusion: It is demonstrated that age estimation in Turkish children and young adults will be performed easier with Modified Demirjian method adapted to the Turkish population.

Keywords: age estimation, modified demirjian method, turkish population, panoramic radiographs, third molar, tooth formation
Volume 3 Issue 6 - 2017

\author{
Ayranci F,' Omezli MM,' Sivrikaya EC,' \\ Cezairli B,' Eroglu A $^{2}$ \\ 'Department of Oral Maxillofacial Surgery, Ordu University, \\ Turkey \\ ${ }^{2}$ Department of Anesthesiology and Intensive Care Medicine, \\ Karadeniz Technical University, Turkey
}

Correspondence: Ahmet Eroglu, Department of Anesthesiology and Intensive Care Medicine, Karadeniz Technical University, Trabzon, Turkey,

Emailerogluah@hotmail.com

Received: November 29, 2016 | Published: June 14, 2017

\section{Introduction}

Children and young adults with the same chronological age may show differences according to the developmental stages of different biological systems. ${ }^{1}$ The development of each individual can be affected by genetic, racial, nutritional, climate, hormonal and environmental factors. ${ }^{2}$ There are various methods for establishing age based on dental tissues, including the following: morphological (dental attrition rate, tooth color changing), metrical (Carbon14 analysis, histological analysis), radio morphological (Demirjian's methods), and radiometric (Cameriere's methods, Mornstaad' methods). ${ }^{3,4}$ These methods are frequently applied in the fields of pediatric dentistry orthodontics and forensic science. ${ }^{5-8}$

Currently, the Demirjian method is the most frequently applied radiological method. ${ }^{8}$ The advantage of the Demirjian's method includes the objective criteria describing stages of tooth development, which have been illustrated with line diagrams and radiographs very clearly. ${ }^{9}$ However, it has been shown that different patterns of dental maturation exist in different populations. ${ }^{1}$ Demirjian's dental age estimation method was done in a different nation successfully but French Canadian studies showing that French Canadian standards were not applicable for age estimation in a different population..$^{5,10-12}$ Although several types of researches have performed with Demirjian method on Turkish population as yet no study has tested this modified Demirjian's method. ${ }^{4,13-15}$

The aim of this study is to adapt the modified Demirjian's method on Turkish children and to research the effect of age and gender on tooth development.

\section{Materials and methods}

Panoramic radiographs of 1182 healthy children aged between 10 and 19years who presented to Ordu University Faculty of Dentistry Department of Oral Maxillofacial Surgery between March 2010 and January 2015 was randomly selected. Of 334 panoramic radiographs with low-resolution quality were excluded from the study. There were totally 848(445 females and 403 males) panoramic radiographs using in the study as children and young adults. The study was explained to the patients and they voluntarily signed a written informed consent. The study design was approved by the Ordu University Ethics Committee.

Exclusion criteria were missing the third molar, the atypical anatomy of third molar, orthodontic treatment, dentoalveolar trauma, any radiographic errors, pathological diseases, craniofacial anomalies or syndromes such as Down syndrome, unilateral hypodontia and the presence of incomplete records or poor quality OPG. Only healthy individuals were included in the study.

The panoramic radiographs were obtained using a Kodak 8000C Digital Panoramic and Cephalometric Extra oral Imaging System (Kodak Dental Systems, Rochester, NY, USA) and images stored in a digital database.

In order to achieve higher accuracy in defining the stages of development towards apexification, the Demirjian method was modified and two stages were added, F1 and G1, making ten stages of the crown and root formation (Figure 1). ${ }^{16}$

The rating was carried out by two examiners (oral medicine and 
research assistant of maxillofacial surgery), date of birth of each study subject was hidden from both the examiners and was blinded from each other. Inter and intra observer's error was calculated and there were no significant differences found. Intra observer's paired Student's t-test $t$ value $=0.30, \mathrm{p}$ value $=1$ and inter observer consistency was rated at $96 \%$, inter observer paired Student's t-test: $t$ value $=0.15$, $\mathrm{p}$ value $=1.48$ with statistical power of 83 .

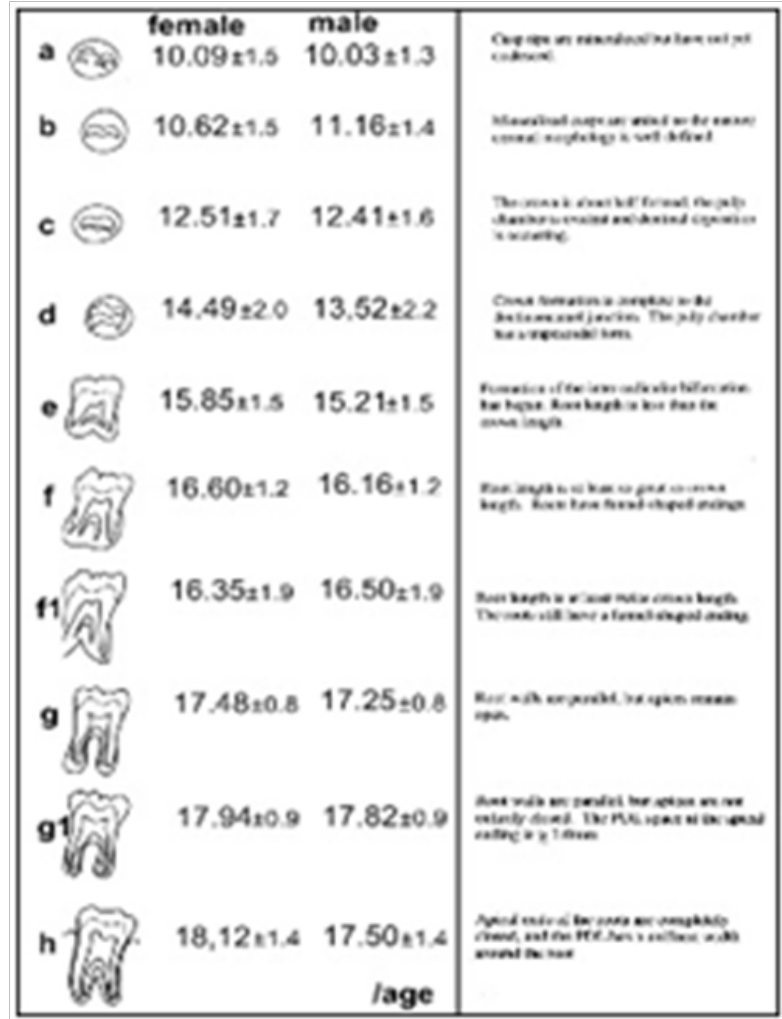

Figure I Schematic drawings and definitions of the ten stages of crown and root formation used to score third molar development and modified demirjian method was adapted to the Turkish population.

Scores of right mandibular wisdom teeth were summed to get the dental maturity score. The chronological age (CA) of each child was calculated by subtracting the date of birth from the date the radiograph was taken. "0". Whenever there was a disparity in the same tooth rated by two or more observers, the earliest formation stage was chosen.

Data were analyzed using the Statistical Package for the Social Sciences (SPSS), Version 20.00 (IBM, Corp, Chicago, Illinois, USA). Mann-Whitney Test was used to test the association between gender and crown-root formation of the third molar for the presentation of patients used in the study.

\section{Results}

Out of total study sample (848), $48 \%(\mathrm{n}=403)$ were males and $52 \%$ $(n=445)$ females of Turkish patients, with an age range from 10 to 19 years. The male and female ratio is almost equal and the data was divided into separate genders (Table 1). The crown and root formation were statistically significant in the 17.0-17.9 age group between females and males $(\mathrm{P}<0.005)$. No statistically significant difference was found in other age groups $(\mathrm{P}<0.005)$ (Table 1).

The scoring table of Demirjian's gives the value of the Turkish children and young adults' chronological age for the ten stages of tooth development, A, 10,03 B, 11,16 C, 12,41 D, 13,52 E, 15,21 F, $16,16 \mathrm{~F} 1,16,50 \mathrm{G}, 17,25 \mathrm{G1}, 17,82 \mathrm{H}, 17,50$ at males and $\mathrm{A}, 10,09$ B, 10,62 C, 12,51 D, 14,49 E, 15,85 F, 16,60 F1, 16,35 G, 17,48 G1, $17,94 \mathrm{H}, 18,12$ at females (Table 2). In Turkish children and young adults, the mean ages at A, C, D, E, F1, G, G1 developmental stage were lower for males than for females and $\mathrm{B}$ and $\mathrm{F}$ were lower for females than males (Figures 1-3).
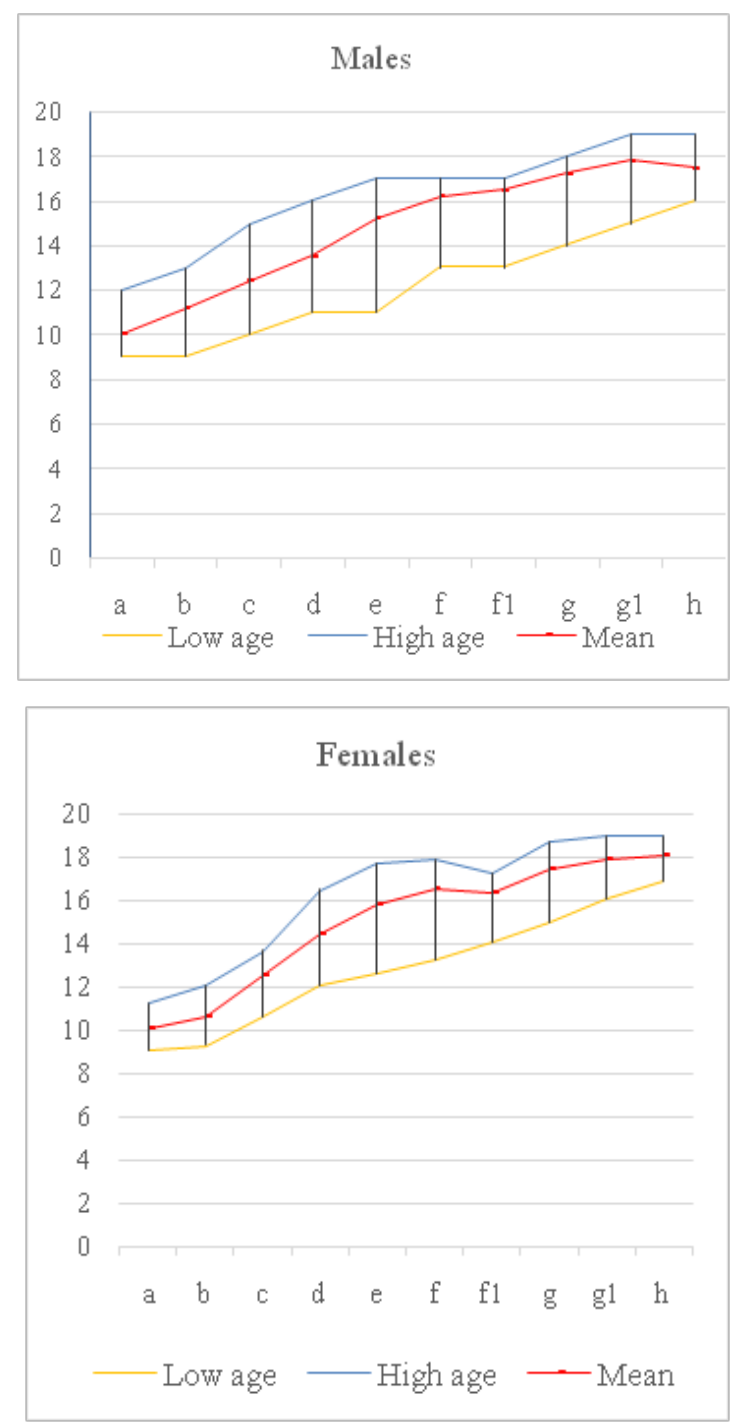

Figure 2 Age intervals according to stages of the patients.

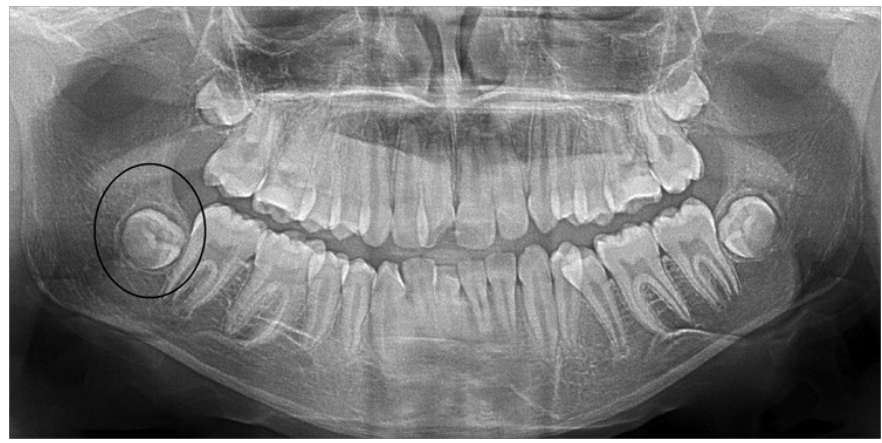

Figure 3 The right third mandibular molars were evaluated with panoramic radiographs (I5years male-Stage $D$ ). 


\section{Discussion}

The Demirjian method is the most widely used method of calculating a dental age. But since the timing of teeth development varies between populations, age estimation analyses should be made in the regions showing the same characteristics.

There are some studies in the literature evaluate the applicability of Demirjian method for Turkish population between 2010 and 2015. ${ }^{13-15,17-19}$ In all studies, the applicability of Demirjian method is not suitable for Turkish population (Table 3). ${ }^{14,15,18}$ Therefore, in the present study, modified Demirjian method is adapted to the Turkish population, (Figures 1-3).

The modified Demirjian stages of tooth development ${ }^{9,16}$ used in this study were designed for third molars. Third molar formation stages were rated because of the absence of other reliable biological markers during late adolescence. Solari et al. ${ }^{16}$ analyzed the stage of third molar development using the eight-grade scheme developed by Demirjian and coworkers and described that In Hispanics, the mean ages at each developmental stage were lower for males than for females. Results of the present study agree with a previous one, the mean ages at A, C, D, E, F1, G, G1 developmental stage were lower for males than for females and $\mathrm{B}$ and $\mathrm{F}$ were lower for females than males (Table 2). This result is confirmed by Zhai, ${ }^{8}$ Gungor, ${ }^{13}$ Solari, ${ }^{16}$ Mincer et al. ${ }^{20}$ Compared with the present study and similar results are seen in the mean ages of the third molar at given stages of tooth development. However, it is observed at all groups that crown-root formation earlier completed in the Turkish children and young adults.

In previous studies conducted in Turkish populations, it has been reported that dentition shows gender differentiation, with that in females preceding that in males..$^{13-15,17,19,21}$ Karadayi et al. ${ }^{19}$ described that this difference was usually in only one stage and not in all teeth. In this study, similarly with Karadayi et al. ${ }^{19}$ females show faster dental maturation than males in one stage (17.0-17.9) $(\mathrm{P}=006)$ (Table 1). With most maturational events, the tempo of maturation is faster in females. ${ }^{22}$

In the present study, F stage and F1 stage are similar age ranges (Figure 1-3).There is a proportional increase in other value ranges, where similar values are seen here suggest that $\mathrm{F}$ runs for a shorter time or that $\mathrm{F}$ and $\mathrm{F} 1$ are confused during the examination.

Table I Distribution of samples based on age and sex

\begin{tabular}{|c|c|c|c|c|c|c|c|c|c|c|}
\hline Age & $10-10.9$ & II-II.9 & | 2-1 2.9 & $13-13.9$ & |4-| 4.9 & $15-15.9$ & $16-16.9$ & $17-17.9$ & $18-18.9$ & $19-19.9$ \\
\hline Male & 39 & 57 & 44 & 39 & 46 & 56 & 34 & 48 & 34 & 6 \\
\hline Female & 39 & 37 & 39 & 37 & 48 & 49 & 54 & 81 & 43 & 18 \\
\hline Sgn & 464 & 118 & 893 & 216 & 491 & 277 & 88 & 6 & 297 & 834 \\
\hline
\end{tabular}

Table 2 Demirjian table was adapted to the Turkish population

\begin{tabular}{|c|c|c|c|c|c|c|c|c|c|c|}
\hline Stages & A & B & C & D & E & $\mathbf{F}$ & FI & G & GI & $\mathbf{H}$ \\
\hline \multicolumn{11}{|l|}{ Males } \\
\hline Mean & $\begin{array}{l}10,03 \\
(37)\end{array}$ & $\begin{array}{l}11,16 \\
(57)\end{array}$ & $\begin{array}{l}|2,4| \\
(75)\end{array}$ & $\begin{array}{l}13,52 \\
(66)\end{array}$ & $\begin{array}{l}|5,2| \\
(68)\end{array}$ & $\begin{array}{l}16,16 \\
(32)\end{array}$ & $16,50(6)$ & $\begin{array}{l}17,25 \\
(16)\end{array}$ & $\begin{array}{l}17,82 \\
\text { (II) }\end{array}$ & $\begin{array}{l}17,50 \\
(20)\end{array}$ \\
\hline SD & $\mathrm{I}, 384$ & $\mathrm{I}, 437$ & 1,628 & 2,214 & I,589 & 987 & 548 & I,29| & 751 & 761 \\
\hline \multicolumn{11}{|c|}{ Females } \\
\hline Mean & $\begin{array}{l}10,09 \\
(23)\end{array}$ & $\begin{array}{l}10,62 \\
(42)\end{array}$ & $\begin{array}{l}|2,5| \\
(65)\end{array}$ & $\begin{array}{l}14,49 \\
(91)\end{array}$ & $\begin{array}{l}15,85 \\
(80)\end{array}$ & $\begin{array}{l}16,60 \\
(40)\end{array}$ & $\begin{array}{l}16,35 \\
(17)\end{array}$ & $\begin{array}{l}17,48 \\
(2 I)\end{array}$ & $\begin{array}{l}17,94 \\
(17)\end{array}$ & $\begin{array}{l}18,12 \\
(17)\end{array}$ \\
\hline SD & $\mathrm{I}, 564$ & $\mathrm{I}, 545$ & I,786 & 2,013 & I,592 & $\mathrm{I}, 277$ & 1,967 & 873 & 966 & 1,409 \\
\hline
\end{tabular}

Table 3 The studies related age estimation between 2010 and 2015 in Turkish population

\begin{tabular}{lllllll}
\hline & Participants & Year & Method & \multicolumn{2}{c}{ Mean difference } & P value \\
\cline { 5 - 7 } & & & & M & F & \\
\hline Gungor et al. $^{13}$ & 535 & 2016 & Demirjian method & $0.04-0.85$ & $0.02-0.79$ & $\mathrm{P}<0.05$ \\
Altunsoy et al. $^{14}$ & 635 & 2015 & Demirjian method & $0.10-0.76$ & $0.28-0.87$ & $\mathrm{P}<0.05$ \\
Celik et al. $^{15}$ & 932 & 2014 & Demirjian method & $1.02-1.69$ & $1.20-1.36$ & $\mathrm{P}<0.05$ \\
Nur et al. $^{18}$ & 673 & 2012 & Demirjian method & $0.86-0.54$ & $0.86-0.54$ & $\mathrm{P}<0.05$ \\
Celikoglu et al. ${ }^{17}$ & 807 & 2010 & Demirjian method & $0.4-1.3$ & $0.2-1.9$ & $\mathrm{P}<0.05$ \\
\hline
\end{tabular}

\section{Conclusion}

Teeth are generally developed earlier in females than in males between 17.0-17.9years. In the present study, modified Demirjian method is adapted to the Turkish population. We suppose that similar studies should be published in different countries in order for the calculation of the dental age to yield more accurate results.

\section{Acknowledgements}

None.

\section{Conflict of interest}

Author declares that there is no conflict of interest. 


\section{References}

1. Leurs IH, Wattel E, Aartman IH, et al. Dental age in Dutch children. Eur J Orthod. 2005;27(3):309-314.

2. Hagg U, Matsson L. Dental maturity as an indicator of chronological age: the accuracy and precision of three methods. Eur J Orthod. 1985;7(1):25-34.

3. Kvaal SI, Kolltveit KM, Thomsen IO, et al. Age estimation of adults from dental radiographs. Forensic Sci Int. 1995;74(3):175-185.

4. Onat Altan H, Altan A, Bilgiç F, et al. The applicability of Willems' method for age estimation in southern Turkish children: A preliminary study. J Forensic Leg Med. 2016;38:24-27.

5. Liversidge HM, Speechly T, Hector MP. Dental maturation in British children: are Demirjian's standards applicable? Int J Paediatr Dent. 1999;9(4):263-269.

6. Schmeling A, Reisinger W, Geserick G, et al. The current state of forensic age estimation of live subjects for the purpose of criminal prosecution. Forensic Sci Med Pathol. 2005;1(4):239-246.

7. Arany S, Iino M, Yoshioka N. Radiographic survey of third molar development in relation to chronological age among Japanese juveniles. J Forensic Sci. 2004;49(3):534-538.

8. Zhai Y, Park H, Han J, et al. Dental age assessment in a northern Chinese population. J Forensic Leg Med. 2016;38:43-49.

9. Demirjian A, Goldstein H, Tanner JM. A new system of dental age assessment. Hum Biol. 1973;45(2):211-227.

10. Koshy S, Tandon S. Dental age assessment: the applicability of Demirjian's method in south Indian children. Forensic Sci Int. 1998;94(1-2):73-85.

11. Prabhakar AR, Panda AK, Raju OS. Applicability of Demirjian's method of age assessment in children of Davangere. J Indian Soc Pedod Prev Dent. 2002;20(2):54-62.

12. Willems G, Van Olmen A, Spiessens B, et al. Dental age estimation in Belgian children: Demirjian's technique revisited. J Forensic Sci. 2001;46(4):893-895.
13. Gungor OE, Kale B, Celikoglu M, et al. Validity of the Demirjian method for dental age estimation for Southern Turkish children. Niger J Clin Pract. 2015;18(5):616-619.

14. Altunsoy M, Nur BG, Akkemik O, et al. Applicability of the Demirjian method for dental age estimation in western Turkish children. Acta Odontol Scand. 2015;73(2):121-125.

15. Celik S, Zeren C, Celikel A, et al. Applicability of the Demirjian method for dental assessment of southern Turkish children. J Forensic Leg Med. 2014;25:1-5.

16. Solari AC, Abramovitch K. The accuracy and precision of third molar development as an indicator of chronological age in Hispanics. $J$ Forensic Sci. 2002;47(3):531-535.

17. Celikoglu M, Cantekin K, Ceylan I. Dental age assessment: the applicability of Demirjian method in eastern Turkish children. J Forensic Sci. 2011;56(Suppl 1):S220-S222.

18. Nur B, Kusgoz A, Bayram M, et al. Validity of demirjian and nolla methods for dental age estimation for Northeastern Turkish children aged 5-16years old. Med Oral Patol Oral Cir Bucal. 2012;17(5):e871e877.

19. Karadayi B, Afşin H, Ozaslan A, et al. Development of dental charts according to tooth development and eruption for Turkish children and young adults. Imaging Sci Dent. 2014;44(2):103-113.

20. Mincer HH, Harris EF, Berryman HE. The A.B.F.O. study of third molar development and its use as an estimator of chronological age. J Forensic Sci. 1993;38(2):379-390.

21. Tunc ES, Koyuturk AE. Dental age assessment using Demirjian's method on northern Turkish children. Forensic Sci Int. 2008;175(1):23-26.

22. Blankenship JA, Mincer HH, Anderson KM, et al. Third molar development in the estimation of chronologic age in american blacks as compared with whites. J Forensic Sci. 2007;52(2):428-433. 